\title{
Studying "Working Fathers": Comparing Fathers' and Mothers' Work-Family Conflict, Fit, and Adaptive Strategies in a Global High- Tech Company
}

E. Jeffrey Hill

Brigham Young University - Provo, jeff_hill@byu.edu

Alan J. Hawkins

Vjollca Märtinson

Brigham Young University - Provo

Maria Ferris

IBM, Global Workforce Diversity

Follow this and additional works at: https://scholarsarchive.byu.edu/facpub

Part of the Other Social and Behavioral Sciences Commons

\section{Original Publication Citation}

Hill, E. J., Hawkins, A. J., Martinson, V., \& Ferris, M. (2003). Studying "Working Fathers":

Comparing fathers' and mothers' work-family conflict, fit, and adaptive strategies in a global high-tech company. Fathering: A Journal of Theory, Research and Practice, 1, 239-261. doi: $10.3149 /$ fth.0103.239

\section{BYU ScholarsArchive Citation}

Hill, E. Jeffrey; Hawkins, Alan J.; Märtinson, Vjollca; and Ferris, Maria, "Studying "Working Fathers": Comparing Fathers' and Mothers' Work-Family Conflict, Fit, and Adaptive Strategies in a Global High-Tech Company" (2003). Faculty Publications. 4046. https://scholarsarchive.byu.edu/facpub/4046

This Peer-Reviewed Article is brought to you for free and open access by BYU ScholarsArchive. It has been accepted for inclusion in Faculty Publications by an authorized administrator of BYU ScholarsArchive. For more information, please contact ellen_amatangelo@byu.edu. 


\section{Studying "Working Fathers": Comparing Fathers' and Mothers' Work-Family Conflict, Fit, and Adaptive Strategies in a Global High-Tech Company}

Hill, E Jeffrey; Hawkins, Alan J; Märtinson, Vjollca; Ferris, Maria . Fathering ; Harriman Vol. 1, Iss. 3, (Oct 2003): 239-261.

¿ProQuest document link

\section{ABSTRACT}

Working fathers are underrepresented-conceptually and empirically-in work-family research. Using a global corporate sample of working fathers from 48 countries $(N=7,692)$, this study compares working fathers to working mothers on key work-family variables as suggested by Voydanoff's (2002) application of ecological systems theory. It examines the direction and the path of the predictors of work-family fit and whether a scarcity or expansion model better explains these results. Finally, it considers what work-family adaptive strategies may affect those relationships. Although fathers consistently reported less family-to-work conflict than mothers, they reported equal amounts of work-to-family conflict. That is, fathers struggled as much as mothers to keep work from draining their energies at home. Similarly, though fathers were less likely than mothers to have used most corporate programs to help find harmony between work and family life, they frequently chose options that provided flexibility in when and where work was done. Overall use of any work-family programs by fathers, including the specific use of flexi-time and flexi-place, were found to be work-family adaptive strategies that predicted greater work-family fit. Having a spouse as the primary caregiver did not predict greater work-family fit for working fathers, but it did for working mothers. Curiously, having greater responsibility for childcare predicted greater work-family fit for fathers but less work-family fit for mothers. These findings have implications for guiding further development of work-family research and programs that include fathers. [PUBLICATION ABSTRACT]

\section{FULL TEXT}

\section{Headnote}

Working fathers are underrepresented-conceptually and empirically-in work-family research. Using a global corporate sample of working fathers from 48 countries $(N=7,692)$, this study compares working fathers to working mothers on key work-family variables as suggested by Voydanoff's (2002) application of ecological systems theory. It examines the direction and the path of the predictors of work-family fit and whether a scarcity or expansion model better explains these results. Finally, it considers what work-family adaptive strategies may affect those relationships. Although fathers consistently reported less family-to-work conflict than mothers, they reported equal amounts of work-to-family conflict. That is, fathers struggled as much as mothers to keep work from draining their energies at home. Similarly, though fathers were less likely than mothers to have used most corporate programs to help find harmony between work and family life, they frequently chose options that provided flexibility in when and where work was done. Overall use of any work-family programs by fathers, including the specific use of flexi-time and flexi-place, were found to be work-family adaptive strategies that predicted greater work-family fit. Having a spouse as the primary caregiver did not predict greater work-family fit for working fathers, 
but it did for working mothers. Curiously, having greater responsibility for childcare predicted greater work-family fit for fathers but less work-family fit for mothers. These findings have implications for guiding further development of work-family research and programs that include fathers.

\section{Headnote}

Key Words: working fathers, work-family conflict, work-family fit, work-family adaptive strategies

Mitch, a talented young man in his late twenties, has established himself in a wellrewarded technical career. He heads an important software development project in a large global corporation, and his income is approaching six figures. Sally, a young woman also in her late twenties, manages a group of technical marketing representatives and is responsible for $\$ 50$ million in revenue. Her income is even higher, about $\$ 125,000$ per year. Two years ago, Mitch and Sally met on the job, fell in love, and got married within the year. They decided to start a family right away, and Sally is expecting their first child in three months. They now face the question, "How will we manage the dramatic changes in our lives associated with a new baby and demanding work?" Their company is near the top of Working Mothers ' list of "Best Companies" to work for and boasts a wide range of family-friendly programs. But when the baby comes, who will take how much time off, and when? Who might seek out a part-time or job-sharing position? Who might explore the option to work at home, scale back his or her career, or even drop out of the labor force for a significant period of time? These are the first of a lifetime of questions to be asked and answered.

Most couples today would probably say that Mitch and Sally should share these important responsibilities equally, or perhaps Mitch should take more responsibility because the dollar value of his work time is lower. The culture, especially in the United States, Australia, and Western Europe, gives lip service to egalitarian gender values. However, the preponderance of work-family research indicates that actual behavior is much more aligned with traditional gender roles (Coltrane, 2000; LaRossa, 1988). Most of the responsibility will likely come to rest squarely on Sally's shoulders, even though she makes more money than her husband.

Understandably, then, most work-family research has focused on mothers' challenges for balancing their work and family lives. Studies rarely look at fathers discretely or focus on the degree to which they experience work-family conflict. That there is no commonly used male counterpart to the term "working mother" is an anomaly in our language illuminated by Levine and Pittinsky (1997) in their book Working Fathers. Barnett (1998) explains that the paucity of work-family research about men reflects "the cultural belief that women's inherent makeup predisposes them to be more reactive and vulnerable to events within the family. The conflict between the demands of the workplace and those of the family will, therefore, be felt more strongly by women and will take a larger toll on them" (p. 127). Researchers point to the small number of men taking paternity leave (Hyde, Essex, \&Horton, 1993) as evidence that men are fundamentally uninterested in greater childcare responsibility (Hood, 1993). Feelings of stress over work-family issues are likewise presumed to be a woman's domain. In parenting workshops, Levine and Pittinsky (1997) found that people estimate that twice as many women as men experience a significant amount of work-family conflict. As Rosalind Barnett remarked, people just assume that a man "never sits at his desk worrying about his kids" (in Levine \&Pittinsky, 1997, p. 19).

As a result, corporations have focused primarily on meeting the needs of working mothers and have assumed that working fathers can fend for themselves. Companies have implemented "working mother" policies such as maternity leave, childcare referral services, part-time employment, telecommuting, and flexible hours (Galinsky \&Bond, 1998). By the late 1980s, these policies were renamed "workfamily" programs, in deference to the possibility that working fathers might use these policies to meet their needs. Yet Levine (2000) argues that men are often expected not to use these programs. If they do, they are at risk for being considered less committed to the organization (Meiksins \&Whalley, 2002). Although Hochschild (1997) notes that many working mothers are 
likewise dissuaded from using work-family programs, informal proscriptions for their use may be even more intense on working fathers.

In addition, almost all work-family research has dealt with subjects from the West (North America, Australia, and the European Union). There has been a bias that, in more traditional cultures and in the developing world, workfamily balance is not a salient issue for employees, much less for working fathers. The point is made that in the developing world, until families have enough food to eat, employees will have little interest in work-family balance even if employers had the resources to offer helpful programs. Moreover, in these traditional cultures we are less likely to find strong beliefs about gender equality and equal partnership between mothers and fathers. However, even in traditional cultures and the developing world, there are growing numbers of relatively affluent individuals with families who work for global companies that have high demands for time and commitment. An unexplored question is whether these individuals will experience work-family issues in ways that are similar to or different from those of their colleagues in the West. To the extent that work-family conflict and fit are experienced in ways similar to their Western counterparts, it reinforces the idea that work-family issues are much more than a cultural phenomenon unique to the West; these issues are deeply personal and familial concerns which are central to individual and family well-being, transcending cultural boundaries.

This study, then, attempts to put working fathers more squarely on the workfamily gender and global research maps. Using global data from a large IBM worklife survey, we focus specifically on how working fathers experience work-family conflict and fit vis-à-vis working mothers, and whether theorized processes link work and family characteristics to work-family conflict and fit in ways similar to those that have been found in research focusing on working mothers. In addition, we explore whether these findings vary by geographic area of the world in an effort to ascertain whether work-family issues transcend cultural boundaries.

\section{CONCEPTUAL MODELS}

We draw upon three conceptual models to guide this study. First, we use an ecological systems theory (cf. Bronfenbrenner, 1986)- and particularly Voydanoff's (2002) application of that theory to work-family research- to select and organize the variables of interest (see Figure 1). Work and family are seen as discrete microsystems through which the individual engages in "networks of face-to-face relationships" (Voydanoff, 2002, p. 138). The reciprocal effects between the work and family microsystems compose what is called the work-family mesosystem. It is proposed there are direct effects of Work and Family Characteristics on Work and Family Outcomes. Work-Family Conflict (both Work-to-Family Conflict and Family-toWork Conflict) is seen as mediating the relationships between Work and Family Characteristics and Work-Family Fit as well as having direct effects on Work and Family Outcomes and Work-Family Fit. Work-Family Adaptive Strategies affect Work-Family Fit and Work and Family Outcomes directly, or may moderate the relationship between Work-Family Conflict and Work and Family Outcomes. This ecological systems model, then, is our framework for selecting variables, organizing our results, and comparing working fathers to working mothers. It helps us examine how the use of work-family policies, particularly those related to flexi-time and flexi-place, influence work-family conflict and work-family fit. The model, however, is best for descriptive purposes; it does not lend itself as well to specific interpretations of why various constructs will relate to each other.

Accordingly, to assist with better prediction and clearer interpretation of our results, we also employ two contrasting conceptual models used widely in the scholarship of work and family life: scarcity and expansion models (Marks, 1977). A scarcity model implies that personal resources, such as time and energy, are limited. Hence, greater participation in multiple, demanding life domains, such as work and family, leads to role overload and dysfunction. A scarcity model explicitly or implicitly undergirds much of the empirical work examining the 
conflict between work and family domains (Higgins, Duxbury, \&lrving, 1992; Kopelman, Greenhaus, \&Connolly, 1983), especially early work in this area, explaining negative spillover from work to family (Kelly \&Voydanoff, 1985) and from family to work (Crouter, 1984). Marks (1977) and others (Sieber, 1974) have also suggested, however, that an expansion model may also operate in people's lives as they not just balance but integrate accumulated roles. Different roles, even when they are demanding ones, can support or energize each other (Thoits, 1986), providing positive spillover (Crouter, 1984). Numerous empirical findings are consistent with this model (see Kirchmeyer, 1992). An intriguing possibility that we consider in this study is that fathers and mothers experience and integrate work and family roles in different ways that are explained by contrasting models. We draw upon scarcity and expansion conceptual models to assist us in understanding possible differences and similarities between fathers and mothers in their experiences of work and family life. These models may also help us understand differences among geographic regions of the world, as well.

\section{REVIEW OF EMPIRICAL LITERATURE}

\section{WORK-FAMILY BALANCE AND WORKING FATHERS}

Relatively few studies have focused specifically on work-family balance and working fathers (Duxbury \&Higgins, $1991)$; the narrow focus of this area of inquiry is potentially a critical gap in work-family research (Parasuraman \&Greenhaus, 2002). Some research explores work-family gender differences, but the results are contradictory. Duxbury and Higgins (1991) found significant differences between fathers and mothers in the strength of numerous paths in a comprehensive work-family model. Parasuraman and Greenhaus cite several studies showing that women experience more conflict than men, but they report similar levels of satisfaction with work and personal/family life. However, Frone, Russell, and Cooper (1992) found that among 16 hypotheses testing a comprehensive model of work-family conflict, there was "no evidence of significant gender differences" (p. 73). Frone (in Quick \&Tetrick, 2003) argues that in many samples with divergent characteristics there are no meaningful gender differences in levels of work-to-family conflict and family-towork conflict. Given the contradictory findings from the research, a thorough comparison of working fathers and working mothers on workfamily variables is in order.

\section{WORK-FAMILY CONFLICT}

Work-family conflict is most frequently defined (Quick \&Tetrick, 2003) as "a form of interrole conflict in which the role pressures from the work and family domains are mutually incompatible in some respect. That is, participation in the work (family) role is made more difficult by virtue of the participation in the family (work) role" (Greenahus \&Beutell, 1985, p. 77). Inherent in this definition is the bi-directional nature of the work-family conflict. There is work-to-family conflict (WFC), where aspects of work life are deleterious to family life, but there is also familytowork conflict (FWC), where aspects of family life are deleterious to work life. However, much research has either been limited to work-to-family conflict (WFC) or has confounded the bidirectionality of the construct. Frone (in Quick \&Tetrick) reports that "the results consistently show that work-to-family conflict is reported to occur more frequently than family -to -work conflict" (p. 149). Countless studies have shown WFC and FWC to be associated with "dissatisfaction and distress within the work and family domains" (Parasuraman \&Greenhaus, 2002). However, few studies have focused specifically on work-family conflict for working fathers.

\section{WORK-FAMILY FIT}

Work-family fit has to do with the individual's overall assessment of how well she or he has been able to integrate paid work and family life. "Individuals derive an overall level of fit by weighting and integrating different 
components of their [workfamily] strategy" (Voydanoff, 2002, p. 155). Barnett (1998) defined fit as "a dynamic process of adjustment between work conditions and the characteristics of workers and their strategies to meet their own needs, as well as the needs of the other people or entities in their social system, and their interconnections" (pp. 143144). Only recently has work-family fit been identified as a separate construct from work-family conflict and the possibility been raised that there could be high workfamily conflict and yet still be high work-family fit (Koch, 2002). For example, a new father may employ strategies to continue to progress in his career at the same time he chooses to take equal responsibility for childcare and housework. To do so may require a lot of strain and much work-to-family and family-to-work conflict. However, if he feels successful at both work and at home, he would be considered to have high work-family fit, even though he experiences high work-family conflict.

\section{WORK-FAMILY ADAPTIVE STRATEGIES}

Some research has documented that if work and family interactions are more flexibly structured in time and space, then outcomes in terms of time, energy, and behavior are generally more positive. Such positive outcomes would be predicted by a scarcity model of work-family life, discussed earlier, because flexible work arrangements are specifically designed to facilitate balancing two domains that compete for the individual's time and energy. Some examples of popular flexible work policies include flexible starting and stopping times, compressed work week, part-time work hours, job sharing, parental leave, work-at-home, the virtual office, and flexible vacation days. Research also shows that flexibility in work arrangements, which enables individuals to integrate and overlap work and family responsibilities in time and space, leads to reduced work-family conflict and is instrumental in achieving a healthy work and family balance (Bond, Galinsky, \&Swanberg, 1998; Hill, Hawkins, \&Miller, 1996).

However, other studies have found that neither access to (Galinsky, Bond, \&Friedman, 1996) nor usage of (Scharlach, 2001) family-friendly programs was related to lower levels of work-family conflict. These non-findings may be more consistent with an expansion model, discussed earlier, which emphasizes an accumulation of meaningful roles, even demanding ones, for positive individual outcomes. In contrast, Galinsky et al. did find an association between schedule control and less conflict. Work-family benefit availability has been found to be related to organizational commitment (Thompson, Beauvais, \&Lyness, 1999) and productivity (Hill, Miller, Weiner, \&Colihan, 1998). We found no studies, however, that focused specifically on working fathers, their use of workfamily programs, and how this use might affect work-family conflict or work-family fit.

\section{RESEARCH QUESTIONS}

Because working fathers are understudied in the work-family literature, this research is exploratory and is guided by research questions designed to build our base of knowledge in this domain. In general, we seek to understand whether there is reason to attend to fathers' experiences of work-family balance by looking discretely at their reports of work-family conflict, fit, adaptation, and outcomes. We compare fathers' reports to mothers' reports, as well as looking across geographic regions to get a sense of how universal these comparisons are. We also look to see if a scarcity model or expansion model better explains the results. We explore the following research questions:

R1. How do working fathers compare vis-à-vis working mothers on key measures of work and family characteristics, work-family conflict, work-family fit, work and family adaptive strategies, and work and family outcomes?

R2. What work-family adaptive strategies do working fathers currently use and intend to use in the future, and how does this usage compare to mothers? 
R3. What are the work and family characteristics that significantly predict workfamily fit for working fathers?

R4. Does work-family conflict mediate the relationship between work and family characteristics and work-family fit for working fathers?

R5. Which work-family adaptive strategies significantly predict greater work-family fit after controlling for work and family characteristics and work-family conflict?

R6. Which work-family adaptive strategies moderate the relationship between work-family conflict and work-family fit for working fathers?

R7. How do measures of work-family conflict, work-family fit, and responsibility for childcare differ among working fathers and working mothers from different geographic regions of the world?

\section{METHOD}

The data for this paper came from the IBM 2001 Global Work and Life Issues Survey. A stratified random sample of 59,250 , representing $20 \%$ of all IBM employees in 48 countries, was invited to take the survey, and 25,822 responded, for a participation rate of $44 \%$. The sample was stratified by gender and by country. Altogether, $31 \%$ of the female population was invited with $43 \%(n=11,244)$ responding; and $15 \%$ of the male population was invited, with $42 \%(n=14,123)$ responding. The reason the participation rate of both men and women was lower than the total participation rate is that some respondents declined to indicate their gender. The questionnaire was translated into 20 different languages. This is the largest known single-issue work-life survey administered by any corporate, governmental, or academic entity.

Because the sample is drawn from a single corporation, it may be useful to briefly review IBM's work and family policies and recent initiatives. During the past two decades, IBM has implemented numerous policies to enable its employees to better harmonize their personal and family needs with the needs of the business. Some of these policies include child and elder care referral services, financial support for near-site dependent care facilities, personal and parental leave policies, online and call-in parenting assistance, permanent part-time job opportunities for professionals and managers, and domestic partner benefits.

More recently, aggressive policies to enhance flexibility in the timing and location of work have been adopted. For example, individualized work schedules give employees the flexibility to start work up to two hours before or after the normal start time at their location with stop times adjusted accordingly. Meal-break flexibility enables employees to take a minimum of 30 minutes or up to a maximum of two hours for a meal break. Compressed workweeks make it possible for employees to work their 40-hour week in fewer than five workdays (e.g., four 10hour days). Beginning in the mid-1990s, IBM began to supply many sales and service employees with the portable means to work from a variety of work locations. About 100,000 IBM employees worldwide no longer had individual company-provided office space (Hill, Ferris, \&Martinson, 2003). Using this virtual office, IBM employees have the flexibility to work whenever and wherever it makes sense. Other recent programs enable substantial numbers of IBM employees to be homebased telecommuters. In 2000, IBM established the Global Workforce Flexibility Project Office to see that flexible work policies were encouraged and established throughout the world.

For this study, a sub-sample of working fathers $(n=7,692)$ with children under age 18 living at home with them at least $50 \%$ of the time was selected. For comparison, a sub-sample of working mothers $(n=4,768)$ was also 
selected. Because so many employees were invited to take the survey, IBM required that the number of questions be limited, to minimize the amount of time respondents spent away from their jobs. Also, the questions had to be approved by human resources management in each part of the world. Because of legal and cultural circumstances, some questions were not asked in all geographic locations.

The survey was administered on the Internet. IBM has conducted online surveys since 1986, and survey data indicate a high degree of confidence in the confidentiality and anonymity of the data. To preserve confidence in anonymity even further, the survey was conducted by a third party, Clear Picture Corporation, which did not communicate any personally identifying information about survey respondents to the IBM survey administrator. Depending on country participation rates, electronic reminder notes encouraging participation were sent two to four times to all survey invitees in their local language. Compared to the pencil-and-paper method, online survey administration at IBM has yielded higher participation rates, more and longer write-in comments on open-ended survey items, quicker data analysis, and faster implementation of new policies based on the data.

\section{MEASUREMENT}

The primary purpose of this company-initiated project was to gather data efficiently on which constructive corporate action could be taken. It was not primarily academic in nature. Hence, in this study single-item measures were frequently required, rather than the preferable multi-item measures or latent constructs. Job Responsibility was the first work characteristic examined in this study ( $1=$ non-manager, $2=$ manager, $3=$ executive $)$. Job Workload was measured with the statement, "The amount of work I am expected to do on my job is: (1 -far too little, 2 = too little, 3 = about right, 4 = too much, 5 = far too much)." Job Travel was measured by the question, "During the last six months, how many nights have you been away from home overnight on IBM business (number of nights)?" Childcare Responsibility was the first family characteristic and was measured by the question, "Who in your household is primarily responsible for caring for children (rearing, transporting, attending school events, etc.) ( 1 = spouse/partner is totally responsible, 2 = spouse/partner is mostly responsible, but I help, 3 = spouse/partner and I are equally responsible, $4=1$ am mostly responsible, but spouse/partner helps, $5=1$ am totally responsible)!" Preschooler at Home was measured by the statement, "Please indicate if you have dependent(s) in the following categories: Age 0-4 ( $0=$ no, $1=$ yes)" Work-to -Family Conflict was measured with the question, "How often do you feel drained when you go home because of work pressures and problems, on a 5 point scale $(1=$ never, $2=$ seldom, 3 = sometimes, 4 = usually, 5 = always)!" Family-to-Work Conflict was measured on the same scale with the question, "How often do you feel drained when you come to work because of personal/family pressures and problems?" Work-Family Fit was measured with the question, "How easy or difficult is it for you to manage the demands of your work and personal/family life? ( 1 = very easy, 2 = easy, 3 = neither easy nor difficult, 4 = difficult, 5 = very difficult)." The work-family adaptive strategies that were measured included ever having used any company work-family programs (WF Programs), reported flexibility in when work is done (Flexi-time, reported on a five-point Likert scale), reported flexibility in where work is done (Flexi-place, also reported on a five-point Likert scale), and the report of using a spouse as the primary childcare provider (Spouse Caregiver). Work and Family Outcomes were each measured on five-point scales. Job Satisfaction was measured with, "Considering everything, how satisfied are you with your job? $(1$ = very dissatisfied, 2 = dissatisfied, $3=$ neither satisfied nor dissatisfied, 4 = satisfied, 5 = very satisfied)." Organizational Commitment was measured with the statement, "Even if I were offered a comparable position with similar pay and benefits at another company, I would NOT leave IBM. (1 = strongly disagree, 2 = disagree, 3 = neither agree nor disagree, 4 = agree, 5 = strongly agree)." Childcare Satisfaction was measured with, "Overall, how satisfied are you with your primary childcare arrangement? $(1=$ very dissatisfied, $2=$ dissatisfied, 3 = neither satisfied nor dissatisfied, 4 = satisfied, 5 = very satisfied)."

\section{RESULTS}


We organize our results around the seven research questions presented earlier.

\section{R1. COMPARISONS OF WORKING FATHERS AND WORKING MOTHERS ON WORK-FAMILY VARIABLES}

Means and standard deviations were calculated for working fathers for all variables in the conceptual model (see Table 1). For comparison, means and standard deviations were also calculated for working mothers, and i-tests were calculated to determine whether significant differences existed. Because the sample size was so large, it is possible to generate statistical significance for these tests with minimal differences. Thus, effect sizes were calculated to provide a measure of the magnitude of the difference between fathers and mothers. They were calculated by dividing the difference between the means by the average of the standard deviations of the means (Shaver, 1991). To minimize drawing attention to statistically significant findings that represent only minimal differences, we discuss only findings with an effect size of .25 or higher. (That is, the difference is at least onequarter of a standard deviation of the distribution for that variable. Hence, our use of the term "significant difference" in this article refers only to differences with an effect size greater than or equal to .25.)

Work and Family Characteristics. Working fathers reported significantly greater job travel than working mothers. They also reported significantly and substantially less childcare responsibility than mothers. The frequencies of responses associated with this item were instructive. As would be expected, $58 \%$ of all parents reported that mothers were mostly responsible for childcare and only $6 \%$ reported that fathers were mostly responsible. However, $36 \%$ reported that mothers and fathers were equally responsible, which means that $42 \%$ of all parents reported that the father in the home was equally or primarily responsible for childcare. The simple report of a mean, in this instance, masks a substantial minority of the working fathers in this sample who have assumed substantial childcare responsibility.

Work-Family Conflict. Working fathers in this sample reported the same high levels of work-to-family conflict as their female counterparts. These non-significant differences are particularly meaningful in light of the very large sample size in this study. In general, interpretation of null hypotheses should be done with caution, but the very large sample size in our study allows us to do so (Keppel, 1991). Other analyses (not shown) reveal that $87 \%$ of the working fathers vs. $88 \%$ of the working mothers reported at least some work-to-family conflict. In contrast, working fathers were significantly less likely to report family-to-work conflict than work-to-family conflict, and significantly less likely than working mothers to report family-to-work conflict. Overall, $42 \%$ of the fathers, compared to $55 \%$ of the mothers, reported at least some family-to-work conflict.

Work-Family Fit. Working fathers' and mothers' work-family fit were not significantly different. Overall, $58 \%$ of the fathers vs. $55 \%$ of the mothers reported workfamily fit, indicating that a majority of both genders did not have difficulty managing the demands of their work and personal/family life.

Work-Family Adaptive Strategies. Working fathers were significantly less likely than mothers to report they had ever used the company's work-family programs. Overall, $34 \%$ of the fathers vs. $58 \%$ of the mothers reported ever having used any of these programs. However, fathers and mothers reported roughly equal levels of flexibility in the timing and place of their work. Finally, and not surprisingly, fathers were much more likely than mothers to report that their spouse was the primary caregiver for their dependent child while they were at work. This was the case for $53 \%$ of the fathers vs. $8 \%$ of the mothers.

Work and Family Outcomes. There were minimal or no differences in reports of working fathers and working mothers on job satisfaction, organizational commitment, and childcare satisfaction. 


\section{R2. WORKING FATHERS CURRENT AND INTENDED USE OF WORK-FAMILY ADAPTIVE STRATEGIES}

Many more fathers report their intention to use work-family programs within the next five years than have actually used them (see Table 2). For example, only $8 \%$ of fathers have ever used an unpaid leave of absence, yet $39 \%$ indicate their intention to use such a program within the next five years. Only $7 \%$ of the fathers reported ever having worked part-time, but $32 \%$ report their intention to do so. About half $(48 \%)$ of the fathers report ever having worked from home during regular business hours, but $82 \%$ report their intention to do so in the future. Working fathers, however, were significantly less likely than working mothers to have used most workfamily adaptive strategies. Although this is also true of fathers' intentions to use these strategies in the next five years, those differences are usually smaller than the differences for past or current use.

\section{R3. WORK AND FAMILY CHARACTERISTICS THAT SIGNIFICANTLY PREDICT WORK-FAMILY FIT}

So far, our analyses have been essentially descriptive in nature. These next analyses go beyond description to prediction of work-family processes to see if theorized processes may exist for working fathers. In Table 3, Step 1, work and family characteristics explained a significant proportion of the variance in Work-Family Fit for fathers $\left(R^{\wedge} \sup 2^{\wedge}=.180\right)$. The strongest predictors were Job Workload $(B=-.349, p<.001)$ and Job Travel $(B=-.145, p$ $<.001)$. With the exception of Childcare Responsibility, these findings for fathers were quite similar to those for mothers. It is interesting, however, that responsibility for childcare was positively associated with greater workfamily fit for fathers $(B=.045, p<.001)$, whereas the association was negative for mothers $(B=-.049, p<.01)$. The resulting interaction is charted in Figure 2. This suggests that gender moderated the relationship between childcare responsibility and work-family fit. It also is evidence that the expansion model may better explain father data and the scarcity model may better explain mother data.

\section{R4. WORK-FAMILY CONFLICT AS A MEDIATOR}

We tested whether Work-Family Conflict mediated the relationship between Work and Family Characteristics and Work-Family Fit for fathers and mothers using criteria specified by Baron and Kenney (1986). First, we found (analyses not shown) that all Work and Family Characteristics except Preschooler at Home significantly predicted Work-to-Family Conflict $\left(\mathrm{R}^{\wedge} \sup 2^{\wedge}=.16\right)$ and all Work and Family Characteristics except Job Responsibility and Preschooler at Home predicted Family-to-Work Conflict $\left(\mathrm{R}^{\wedge} \sup 2^{\wedge}=.01\right)$, for both fathers and mothers. Second, we found that all Work and Family Characteristics significantly predicted Work-Family Fit (See Table 3, Step 1) for both fathers and mothers. Third, we added the Work-to-Family Conflict variables to the regression equation and found that they affected Work-Family Fit (See Table 3, Step 2). To verify that there were no multicollinearity problems, we found that Work-to-Family Conflict and Family-to-Work Conflict were reasonably independent of one another $(r=.31)$. Adding these two indicators of work-family conflict increased the explanatory power of the model $\left(\mathrm{R}^{\wedge} \sup 2^{\wedge}=.267, \mathrm{R}^{\wedge} \sup 2^{\wedge}=.087\right)$. We then checked to see what cases of full mediation (where a relationship which had been significant was no longer significant after adding the mediator) and partial mediation (where the relationship remained significant but was reduced substantially after adding the mediator) might exist. We found one case of full mediation for mothers. The significant negative relationship between Responsibility for Childcare and Work-Family Fit became insignificant after controlling for Work-Family Conflict. There were no cases of full mediation for fathers. It appeared Work-Family Conflict also partially mediated the negative relationship of Job Workload with Work-Family Fit for fathers and mothers. 
Next, we examined which of four Work-Family Adaptive Strategies predicted improved Work-Family Fit after controlling for Work and Family Characteristics and Work-Family Conflict. As mentioned, fathers were less likely to report that they had ever used company work-family programs. Moreover, the use of such programs added almost nothing to the prediction of greater Work-Family Fit ( $B=.060, p<.001, R^{\wedge}$ sup $2^{\wedge}=.003$ ). The Use Any Work-Family Programs was a stronger predictor of Work-Family Fit for mothers $\left(B=.089, p<.001, R^{\wedge}\right.$ sup $\left.2^{\wedge}=.008\right)$. Fathers, however, reported that more Flexi-time $\left(B=.141, p<.001, R^{\wedge}\right.$ sup $\left.2^{\wedge}=.021\right)$ and Flexi-place $\left(B=.178, p<.001, R^{\wedge}\right.$ sup $\left.2^{\wedge}=.033\right)$ contributed to better Work-Family Fit, and these predictors were slightly stronger for fathers than mothers. Spouse Caregiver did not contribute to significantly greater Work-Family Fit for working fathers (though it did for mothers who had husbands as primary caregivers).

\section{R6. WHICH WORK-FAMILY ADAPTIVE STRATEGIES MODERATE WORK-FAMILY CONFLICT?}

To answer this research question, we created eight interaction terms combining the four Work-Family Adaptive Strategies by Work-to-Family Conflict and by Familyto-Work Conflict. We added these eight interaction terms to the regression equations in Table 3 predicting Work-Family Fit for fathers and mothers. Though we found no significant interactions for mothers, we found two significant interactions for fathers. First, Flexi-time as a WorkFamily Adaptive Strategy moderated the negative relationship between Work-to-Family Conflict and Work-Family Fit $(p<.05)$. That is, those fathers with more flexibility in hours they work maintained higher levels of work-family fit in the face of higher levels of work-to-family conflict than those with lower levels of this flexibility. Second, Spouse Caregiver proved to be a Work-Family Adaptive Strategy that moderated the negative relationship between Familyto-Work Conflict and Work-Family Fit $(p<.05)$. That is, those fathers with wives caring for their children during working hours maintained higher levels of Work-Family Fit in the face of higher levels of Family-to-Work Conflict.

\section{R7. GEOGRAPHIC COMPARISON OF WORK-FAMILY CONFLICT, FIT, AND CHILDCARE RESPONSIBILITY}

In this last set of analyses (see Table 4), we return to essentially descriptive analyses to explore global similarities and differences in experiences of work-family issues.

Work-to-Family Conflict (WFC). We found no meaningful differences in reported WFC between working fathers and working mothers in any region of the world. It should be noted that Asian fathers (and mothers) by far reported the highest levels of WFC of any region in the world. Fathers (and mothers) in Scandinavia reported the least WFC.

Family-to-Work Conflict. In all geographic regions, except for Eastern Europe and Scandinavia, fathers reported significantly less FWC than mothers. Working fathers (and mothers) from Asia also reported the highest levels of FWC. Working fathers (but not mothers) from Eastern Europe reported the least FWC.

Work-Family Fit. With the exception of Asia, working fathers were not significantly different from working mothers in their reports of Work-Family Fit. In Asia, working fathers reported significantly greater Work-Family Fit than working mothers. Working fathers (and mothers) from Scandinavia reported the greatest Work-Family Fit.

Responsibility for Childcare. In every geographic region, working fathers reported substantially lower levels of Responsibility for Childcare than working mothers (analyses not shown). However, this overall finding masks the fact that large numbers of working fathers are taking at least half of the Responsibility for Childcare. Overall, Scandinavia, with its aggressive public policies that promote fathers' involvement in domestic work, reported the most egalitarian division of Responsibility for Childcare $(61 \%$ of the fathers reported to be taking at least half of the responsibility), and Eastern Europe reported the least (33\%). 
The stated purpose of this study is to put working fathers more squarely on the global work-family research map. Using global data from a large IBM work-life survey, we focused specifically on how working fathers experience Work-Family Conflict vis-à-vis working mothers, whether theorized processes link Work and Family Characteristics to Work-Family Conflict and Work-Family Fit for working fathers, and whether this varies by geographic area of the world.

Fundamentally, this study reveals that working fathers are a legitimate focus of work-family research. A scarcity model of work-family life predicts that individuals will straggle to integrate two demanding roles, and fathers report straggling just as much with work-to-family conflict as working mothers do, and are just as likely to have difficulty with work-family fit. These findings hold true throughout the world, except in the more traditional cultures of Asia and Latin America. There also appears to be a need for adaptive work and family strategies for working fathers, just as there is for working mothers, though the nature of those strategies may differ.

On average, working fathers take substantially less responsibility for childcare than working mothers do. But these data show that nearly half of all fathers throughout the world (42\%) have enacted an egalitarian value of sharing childcare responsibility at least equally. These data include the reports of working mothers and so this finding is more objective than just the self -report of working fathers. In some parts of the world, this egalitarian trend is well established. In Scandinavia, nearly twothirds of fathers (61\%) have at least half of the responsibility for childcare. This indicates that public policy, such as Scandinavian national policy initiatives on father involvement, may influence fathers' behavior. For example, Sweden and Norway adopted a generous take-it-or-lose-it paternity leave benefit that strongly facilitated men staying home with their infants for a period of time (Haas, 1996).

This study also reveals that some work-family programs may be more "fatherfriendly" than others. Programs focusing on childcare and reduced hours are much less likely to be used by fathers than by mothers. Compared to mothers, fathers were only one-tenth as likely to have ever used parenting leave, one-sixth as likely to have ever used part-time work hours, and about half as likely to have ever used childcare referral services. However, workfamily programs focusing on flexibility in when and where work is done are well used by fathers and positively mediate the relationship between work and family characteristics and work-family fit.

An intriguing finding of the study is the relationship between responsibility to care for dependent children and work-family fit. From a scarcity model perspective, one would speculate that greater childcare responsibility would make it more difficult to integrate work-family demands successfully. In fact, the impetus for many work-family programs has been to help the parent who has childcare responsibilities (usually the mother) achieve greater workfamily fit. Consistent with a scarcity model, the results for mothers show greater childcare responsibility is negatively related to work-family fit. However, for fathers, the opposite is shown. Greater childcare responsibility is actually related to improved work-family fit. This finding is more consistent with an expansion model that allows for multiple demanding roles to be supportive and energizing of each other. Other perspectives, consistent with the expansion model, may help explain this difference, too. Another possibility is that many fathers, especially in dualcareer families, feel uncomfortable that they are not meeting the new egalitarian culture of fatherhood. Perhaps those fathers who assume more childcare responsibility reduce this cognitive dissonance and report that as greater work-family fit. Another possibility is that the family is a place of greater rejuvenation for fathers compared to mothers, and that involvement in childcare- albeit at generally lower levels of involvement- stimulates that rejuvenation. Whatever the reason, the implication is that if companies can encourage fathers to take equitable responsibility for the care of their children, they may also help them to achieve better work-family fit. 
An expansion model also helps explain two other intriguing, modest differences between fathers and mothers in our study. The use of work-family programs, such as childcare referral or on-site daycare, was more helpful for working mothers than for working fathers. Similarly, the presence of a spouse who was a primary caregiver increased work-family fit for mothers but not for fathers. A scarcity model predicts that, given the limited resources individuals have, these kinds of programs should reduce stress and increase work-family fit, as they do for mothers. But this pattern is weak for fathers. Again, there is intriguing evidence that a scarcity model of workfamily life is somewhat stronger for mothers than fathers, and that the expansion of the domestic role for fathers is supportive of their work role.

However, we should be cautious about stressing these gender differences at the expense of the dominant pattern in our findings of similar work-family experiences of mothers and fathers. The main implication for business organizations is that fathers are an integral part of the work-family map. The data clearly document that, for fathers, work-to-family conflict is strongly related to work-family fit, which has been shown to relate to such valued business outcomes as job satisfaction and job commitment. If businesses want to attract, motivate, and retain fathers who possess strategic talent, they should address these issues in a way that will sound a responsive chord with fathers. The data from this study show that fathers favor flexibility in when and where work is done over the traditional work-family programs that emphasize assisting with responsibilities for childcare. This flexibility in when work is done is particularly helpful for fathers. This study shows it weakens the negative link between workto-family conflict and work-family fit. In developing work-family programs, human resource planners should take into account the differing needs and wants of fathers.

Moreover, fathers were significantly less likely than mothers to report feeling drained at work because of family pressures and problems, but fathers were just as likely to report feeling drained at home because of work pressures and problems. In other words, the psychological spillover of work to home is a more salient dimension for fathers' work-family balance. The role conflict predicted by a scarcity model of work-family life may not be as bi-directional for fathers as it is for mothers. Greater involvement in the family domain may even support more positive experiences at work for fathers but not so for mothers, who already generally take on a larger share of that domestic work. Programs to help employees manage this work-family strain at home are less developed and implemented than programs that assist with family-to-work spillover, even in the most "family-friendly" companies. Programs that pay specific attention to helping fathers (and mothers) manage the stress of work and leave it at the office may yield strategic benefits in terms of greater work satisfaction and organizational commitment.

Finally, it is also worth noting that this study provides evidence that work-family conflict is not just a cultural quirk unique to affluent and Western nations. Rather, the experience of work-family conflict, as well as positive spillover between these domains, appears widespread. Variation exists, of course. But the challenges of balancing the sometimes competing demands of modern work with contemporary family life, however it is culturally constructed, certainly appear relatively impervious to geographic boundaries. That is, work-family conflict (and work-family support) is generated less by cultural ideals about how work and family should go together than by the very nature of everyday work and family life itself.

\section{LIMITATIONS}

Although this study has unique strengths, it also has clear weaknesses. The respondents in this study all worked for IBM. IBM employees throughout the world tend to be more highly educated, have higher salaries, and have more experience with computer technology than the general population. For these reasons, the degree to which these results may be generalized to other companies is uncertain. However, this is not necessarily a weakness. Hofstede's (1980) influential work also used solely IBM data from 40 countries and claimed it was a benefit that 
enabled him to control for company effects. One clear limitation is that because of the limited number of questions that could be asked, single-item measures had to be used in the analyses instead of validated scales that could more reliably and richly measure the constructs of interest. Also, in this study we have not formally tested the validity of Voydanoff s (2002) model with fathers, nor used sophisticated analyses to compare the fit of those models for both fathers and mothers. That analytic task is beyond the descriptive scope of this study, but will be important to future research.

Nevertheless, our relatively simple analyses of a unique data set provide support for researchers and corporate policymakers to take the construct of "working fathers" seriously. There are striking similarities between working fathers and working mothers as well as noteworthy differences in their reports about work-family issues. But our study provides ample reason to take the study of work-family issues beyond "working mothers." Moreover, the fact that work-family issues are evident for fathers across the globe reinforces the possibility that these issues are fundamental, perhaps even universal, for families and work organizations.

\section{References}

\section{REFERENCES}

Barnett, R.C. (1998). Toward a review and reconceptualization of the work/family literature. Genetic, Social, and General Psychology Monographs, 124, 125-182.

Baron, R.M., \&Kenny, DA. (1986). The moderator-mediator variable distinction in social psychological research: Conceptual, strategic, and statistical considerations. Journal of Personality and Social Psychology, 51, 1 173-1 182.

Bond, J.T., Galinsky, E., \&Swanberg, J.E. (1998). The 1997 National Study ofthe Changing Workforce. New York: Families and Work Institute.

Bronfenbrenner, U. (1986). Ecology of the family as a context for human development: Research perspectives. Developmental Psychology, 22, 723-742.

Coltrane, S. (2000). Research on household labor. Journal of Marriage and the Family, 62, 1209-1233.

Crouter, A.C. (1984). Spillover from family to work: The neglected side of the work-family interface. Human Relations, 37, 425-442.

Duxbury, L.E., \&Higgins, CA. (1991). Gender differences in work-family conflict. Journal of Applied Psychology, 76(1), 60-74.

Frone, M. R., Russell, M., \&Cooper, M. L. (1992). Antecedents and outcomes of work-family conflict: Testing a model of the work-family interface. Journal of Applied Psychology, 77(1), 65-78.

Galinsky, E., Bond, J. T., \&Friedman, D.E. (1996). The role of employers in addressing the needs of employed parents. Journal of Social Issues, 52(3), 111136.

Galinsky, E., \&Bond, JT. (1998). The 1998 business work-life study: A sourcebook. New York: Families and Work Institute.

Greenhaus, J.H., \&Beutell, N.J. (1985). Sources of conflict between work and family roles. Academy of Management Review, 10(1), 76-88.

Haas, L. (1996). Family policy in Sweden. Journal of Family and Economic Issues, 17,41-91.

Higgins, CA., Duxbury, L. E., \&lrving, R. H. (1992). Work-family conflict in the dual-career family. Organizational Behavior and Human Decision Processes, 51, 51-75.

Hill, E.J., Hawkins, A.J., \&Miller, B.C. (1996). Work and family in the virtual office: Perceived influences of mobile telework. Family Relations, 45, 293-301.

Hill, E.J., Ferris, M., \&Martinson, V. (2003). Does it matter where you work?: A comparison of how three work venues (traditional office, virtual office and home office) influence aspects of work and work/family balance. Journal of Vocational Behavior, 63(2), 220-241.

Hill, E.J., Miller, B.C., Weiner, S.P., \&Colihan, J. (1998). Influences of the virtual office on aspects of work and 
work/life balance. Personnel Psychology, 51 , 667-683.

Hochschild, A. R. (1997). The time bind. New York: Metropolitan Books.

Hofstede, G. (1980). Culture's consequences: International differences in workrelated values. Beverly Hills, CA: Sage.

Hood, J.C. (Ed.). (1993). Men, work, and family. Newbury Park: Sage Publications.

Hyde, J. S., Essex, M.J., \&Horton, F. (1993). Fathers and parental leave: Attitudes and experiences. Journal of Family Issues, 14, 616-641.

Kelly, R., \&Voydanoff, P. (1985). Work family role strain among employed parents. Family Relations, 34, 367-374.

Keppel, G. (1991). Design and analysis: A researcher's handbook. Englewood Cliffs, NJ: Prentice Hall.

Kirchmeyer, C. (1992). Perceptions of nonwork-to-work spillover: Challenging the common view of conflict-ridden domain relationships. Basic and Applied Social Psychology, 73,231-249.

Koch, L. (2002). Balance and conflict: Variation in attaining work-family fit among a homogeneous population.

Provo, UT: Brigham Young University.

Kopelman, R.E., Greenhaus, G.H., \&Connolly, T. F. (1983). A model of work, family, and interrole conflict: A construct validation study. Organizational Behavior and Human Performance, 32, 198-221.

LaRossa, R. (1988). Fatherhood and social change. Family Relations, 37, 451-457.

Levine, S. B. (2000). Father courage: What happens when men put family first. New York: Harcourt.

Levine, J., \&Pittinsky, T. (1997). Working fathers: New strategies for balancing work and family. Reading, MA:

Addison Wesley.

Marks, S. R. (1977). Multiple roles and role strain: Some notes on human energy, time and commitment. American Sociological Review, 42, 921-936.

Meiksins, P., \&Whalley, P. (2002). Putting work in its place: A quiet revolution. Ithaca, NY: Cornell University Press. Parasuraman, S., \&Greenhaus, J.H. (2002). Toward reducing some critical gaps in work-family research. Human Resource Management Review, 12, 299-312.

Quick, J.C., \&Tetrick, L. E. (Eds.). (2003). Handbook of occupational health psychology. Washington, DC: APA.

Scharlach, A. E. (2001). Role strain among working parents: Implications for workplace and community.

Community, Work \&Family, 4, 215-230.

Shaver, J.P. (1991). Handbook of research on social studies. New York: Macmillan Publishing Company.

Sieber, S.D. (1974). Toward a theory of role accumulation. American Sociological Review, 39, 567-578.

Thoits, PA. (1986). Multiple identities: Examining gender and marital status differences in distress. American Sociological Review, 51, 259-272.

Thompson, CA., Beauvais, L.L, \&Lyness, K.S. (1999). When work-family benefits are not enough: The influence of work-family culture on benefit utilization, organizational attachment, and work-family conflict. Journal of Vocational Behavior, 54, 392-415.

Voydanoff, P. (2002). Linkages between the work-family interface and work, family, and individual outcomes: An integrative model. Journal of Family Issues, 23, 138-164.

\section{AuthorAffiliation}

E. JEFFREY HILL

Brigham Young University

IBM, Global Workforce Diversity

ALAN J. HAWKINS

VJOLLCA MARTINSON

Brigham Young University

MARIA FERRIS

IBM, Global Workforce Diversity 


\section{AuthorAffiliation}

We thank International Business Machines Corporation (IBM) for providing the support and cooperation needed to collect the data used in this article. Ideas expressed are the opinions of the authors, not necessarily of IBM.

Correspondence concerning this article should be addressed to E. Jeffrey Hill, School of Family Life, Brigham Young University, P.O. Box 25524, Provo, UT 84602-5524. Electronic mail: jeff_hill@byu.edu.

\section{DETAILS}

Subject:

Working mothers; Maternity \&paternity leaves; Studies; Research \&development--R \&D; Men

Publication title:

Fathering; Harriman

Volume:

1

Issue:

3

Pages:

239-261

Number of pages:

23

Publication year:

2003

Publication date:

Oct 2003

Publisher:

Men's Studies Press

Place of publication: Harriman

Country of publication: United States, Harriman

Publication subject: $\quad$ Children And Youth - About, Sociology

ISSN:

15376680

e-ISSN:

1933026X

Source type: $\quad$ Scholarly Journals

Language of publication: English

Document type: $\quad$ Feature

Document feature: $\quad$ Charts Tables Graphs References

DOI:

http://dx.doi.org/10.3149/fth.0103.239

ProQuest document ID: 222669116 
Copyright:

Last updated:

Database:

\section{LINKS}

Linking Service
Copyright Men's Studies Press Oct 2003

2018-10-06

GenderWatch,Social Science Premium Collection

Database copyright $\odot 2020$ ProQuest LLC. All rights reserved.

Terms and Conditions Contact ProQuest 